passive smoking by the Tobacco Advisory Group of the Royal College of Physicians. London: RCP, 2005.

15 Jarvis MJ. Application of biochemical intake markers to passive smoking measurement and risk estimation. Mutat Res 1989;222:101-10.

16 Jarvis MJ, Primatesta P, Erens B, Feyerabend C, Bryant A. Measuring nicotine intake in population surveys: comparability of saliva cotinine and plasma cotinine estimates. Nicotine Tob Res 2003;5:349-55.

17 Currie C, Elton RA, Todd J, Platt S. Indicators of socioeconomic status for adolescents: the WHO health behaviour in school-aged children survey. Health Educ Res 1997;12:385-97.

18 Boyce W, Dallago L. Socioeconomic inequality. In: Currie CE, Roberts C, Morgan A, Smith R, Settertobulte W, Samdal O, et al, eds. Young people's health in context: health policy for children and adolescents No 4. Copenhagen, Denmark: WHO Regional Office for Europe, 2004:13-25.

19 Batista-Foguet JM, Fortiana J, Currie C, Villalbi JR. Socioeconomic indexes in surveys for comparisons between countries: an applied comparison using the family affluence scale. Soc Indic Res 2004;67:315-32.

20 Hetland J, Aarø LE. Smokefree restaurants and pubs: air quality, self reported health and job satisfaction. Evaluation of smoking control policies in Norway, 2003-2007. HEMIL/SIRUS report No 4, 2005.

21 Jarvis MJ, Goddard E, Higgins V, Feyerabend C, Bryant A, Cook DG. Children's exposure to passive smoking in England since the 1980s: cotinine evidence from population surveys. BMJ 2000;321:343-5.

22 Department of Health. Health survey for England. www.dh.gov.uk/ en/Publicationsandstatistics/PublishedSurvey/ HealthSurveyForEngland/index.htm (accessed 22 June 2007).

23 Bromley C, Sproston K, Shelton N. The Scottish health survey 2003. Volume 3: children. Edinburgh: Scottish Executive, 2005. Available at www.scotland.gov.uk/Resource/Doc/76169/0019732.pdf.

24 Kallio K, Jokinen E, Raitakari OT, Hämäläinen M, Siltala M, Volanenn I, et al. Circulation 2007;115:3205-12.

Accepted: 15 August 2007

\title{
Changes in exposure of adult non-smokers to secondhand smoke after implementation of smoke-free legislation in Scotland: national cross sectional survey
}

\author{
Sally J Haw, Laurence Gruer ${ }^{2}$
}

\section{EDITORIAL by Chapman RESEARCH pp 545, 553}

${ }^{1} \mathrm{NHS}$ Health Scotland,

Edinburgh EH12 5EZ

${ }^{2} \mathrm{NHS}$ Health Scotland,

Glasgow G3 7LS

Correspondence to: S Haw

Sally.Haw@health.scot.nhs.uk

BMJ 2007;335:549-52

doi:10.1136/bmj.39315.670208.47

This article is an abridged version of a paper that was published on bmj.com on 10 September 2007. Cite this version as: $B M J 10$ September 2007, doi: 10.1136/ bmj.39315.670208.47 (abridged text, in print: $B M J$ 2007;335:549-52).

\section{ABSTRACT}

Objective: To measure change in adult non-smokers' exposure to secondhand smoke in public and private places after smoke-free legislation was implemented in Scotland.

Design: Repeat cross sectional survey.

Setting: Scotland.

Participants: Scottish adults, aged 18 to 74 years, recruited and interviewed in their homes.

Intervention: Comprehensive smoke-free legislation that prohibits smoking in virtually all enclosed public places and workplaces, including bars, restaurants, and cafes.

Outcome measures: Salivary cotinine, self reported exposure to smoke in public and private places, and self reported smoking restriction in homes and in cars.

Results: Overall, geometric mean cotinine concentrations in adult non-smokers fell by $39 \%$ (95\% confidence interval $29 \%$ to $47 \%$ ), from $0.43 \mathrm{ng} / \mathrm{ml}$ at baseline to $0.26 \mathrm{ng} / \mathrm{ml}$ after legislation (P<0.001). In non-smokers from nonsmoking households, geometric mean cotinine concentrations fell by $49 \%$ ( $40 \%$ to $56 \%$ ), from $0.35 \mathrm{ng} / \mathrm{ml}$ to $0.18 \mathrm{ng} / \mathrm{ml}(\mathrm{P}<0.001)$. The $16 \%$ fall in cotinine concentrations in non-smokers from smoking households was not statistically significant. Reduction in exposure to secondhand smoke was associated with a reduction after legislation in reported exposure to secondhand smoke in public places (pubs, other workplaces, and public transport) but not in homes and cars. We found no evidence of displacement of smoking from public places into the home.

Conclusions: Implementation of Scotland's smoke-free legislation has been accompanied within one year by a large reduction in exposure to secondhand smoke, which has been greatest in non-smokers living in non-smoking households. Non-smokers living in smoking households continue to have high levels of exposure to secondhand smoke.

\section{INTRODUCTION}

On 26 March 2006 comprehensive legislation was implemented in Scotland to prohibit smoking in virtually all enclosed public places and workplaces, including bars, restaurants and cafés. ${ }^{1}$ A subsequent study of air quality in a random sample of 41 pubs in Scotland has reported an overall $86 \%$ reduction in small airborne particles $\left(\mathrm{PM}_{2.5}\right)$ - an air marker of secondhand smoketwo months after implementation of the legislation. ${ }^{2}$ This is consistent with studies from other countries where similar legislation has been introduced. ${ }^{34}$

Our study is part of a comprehensive evaluation of Scotland's smoke-free legislation. ${ }^{5}$ It aimed to determine if a measurable change occurred in exposure to secondhand smoke in adult non-smokers after implementation of the Scottish smoke-free legislation; to assess whether overall changes in secondhand exposure were related to exposure in public or private spaces; and to determine if any evidence existed of increased exposure to secondhand smoke among non-smokers living with smokers, associated with displacement of smoking into the home.

\section{METHODS}

\section{Survey}

Data on adult exposure to secondhand smoke were collected as part of the health education population survey, using a repeat cross sectional design before and after implementation of the legislation. This survey has been conducted in most years since 1996 to monitor health related knowledge and behaviour. ${ }^{6}$ Data are collected twice a year in two waves. For this study, survey waves conducted between 1 September and 20 November 2005 and between 9 January and 25 March 2006 
provided baseline data. Post-legislation data were collected in two waves between 1 September and 10 December 2006 and between 8 January and 2 April 2007.

Addresses from mainland Scotland were selected from the Royal Mail's postal address file using a rolling, multistage, clustered random sampling strategy. See bmj.com for sampling strategy.

One week before the start of fieldwork, a letter was sent to all selected addresses informing the occupier that the household had been chosen to take part in the survey and that an interviewer would be calling on them in the near future.

People aged 16 to 74 years were eligible to participate in the study.

\section{Interviews}

Study participants were interviewed at home by trained interviewers. Data on a range of health behaviours were collected by using computer assisted personal interviewing. The smoking module included self reported smoking status, date of cessation, and use of nicotine replacement therapy. Data were collected on the participants' experience of smoking restrictions in public places (work, pubs, and public transport) and private places (home and car) and on reported exposure to secondhand smoke in these different locations. The questionnaire is available at www.healthscotland. com/scotlands-health/evaluation/policy-evaluation/ smoking.aspx. All respondents were asked to provide a sample of saliva to test for cotinine, a metabolite of nicotine, and a stable, highly specific and sensitive biomarker of both active and passive absorption of tobacco smoke (see bmj.com).

\section{Definition of smoking status and the assessment of outcomes}

We based assessment of change in exposure to secondhand smoke in non-smokers on self reported non-smoking status (never smoker or ex-smoker), confirmed by salivary cotinine concentration. Respondents who were using nicotine replacement therapy were excluded from the analysis, as were "smoking deceivers"-respondents who reported that they were non-smokers but had a cotinine concentration above $15 \mathrm{ng} / \mathrm{ml}$, the accepted threshold for active smoking. Assessments of changes in location of exposure to secondhand smoke and smoking restriction in homes and cars in non-smokers are based on self reported smoking status alone.

\section{RESULTS}

Sample

The response rates in the four successive waves- $70 \%$, $71 \%, 66 \%$, and $71 \%$ - compare well with other UK national surveys, which have response rates of around $66 \% .^{78} \mathrm{~A}$ total of 1815 participants were recruited to the baseline survey and 1834 to the post-legislation survey. The profiles of the weighted samples were similar in sex, age, marital status, and smoking status. However, respondents in the post-legislation sample were more likely to have more than 11 years' education $(\mathrm{P}<0.01)$ and less likely to live in the most deprived areas $(\mathrm{P}<0.001)$.

The prevalence of smoking was $35.6 \%$ (646/1815) in the pre-legislation sample and $35.1 \%(644 / 1834)$ in the post-legislation sample. Exclusion of smokers yielded final sample sizes of 1170 before legislation and 1190 after legislation. Baseline characteristics of the two samples were similar, but the non-smokers recruited after implementation of the legislation were less likely to live in the most deprived areas $(\mathrm{P}<0.001)$ (see bmj.com).

\section{Provision of saliva sample for testing for cotinine}

Valid cotinine measurements were available for 627 $(53.6 \%)$ baseline respondents and $592(49.7 \%)$ respondents recruited after the legislation. Compared with those who did not, respondents who had a valid cotinine measurement were more likely to be male $(50.5 \%$ $v 49.5 \% ; \mathrm{P}<0.05)$ and have 11 or more years of education $(53.7 \%$ v $45.6 \% ; \mathrm{P}<0.001)$. They were also less likely to be 55 years or older $(26.8 \%$ v $30.2 \%$; $\mathrm{P}<0.01)$ and to live in areas in Carstairs deprivation categories 6 and $7(10.6 \%$ v $14.6 \% ; \mathrm{P}=0.001)$ (see table 1 on bmj.com).

\section{Changes in exposures to secondhand smoke in adult non-smokers}

Cotinine measurements for 627 non-smokers recruited pre-legislation and 592 non-smokers recruited postlegislation were analysed to assess change in exposure to secondhand smoke. Before legislation the median and mode values were $0.4 \mathrm{ng} / \mathrm{ml}$ and $0.3 \mathrm{ng} / \mathrm{ml}$ respectively, with a range of $<0.1 \mathrm{ng} / \mathrm{ml}$ (below the level of detection) to $10.5 \mathrm{ng} / \mathrm{ml}$. After legislation the range was wider $(<0.1 \mathrm{ng} / \mathrm{ml}$ to $13.7 \mathrm{ng} / \mathrm{ml})$ but the median fell to $0.2 \mathrm{ng} / \mathrm{ml}$ and the mode to $<0.1 \mathrm{ng} / \mathrm{ml}$. The distribution of cotinine values shifted (figure), with an increase in the proportion of samples below the level of detection $(0.1 \mathrm{ng} / \mathrm{ml})$, from $11.3 \%$ (71 samples) before legislation to $27.6 \%$ (165) afterwards.

The impact of the smoke-free legislation on exposure to secondhand smoke (log cotinine) was evaluated using analysis of covariance. Two independent variables (smoking ban and household smoking status (non-smoking household $v$ households with at least one smoker)) and three covariates (sex, years in education, and deprivation category of residence) were included in the model.

The overall geometric mean cotinine for non-smokers fell from $0.43 \mathrm{ng} / \mathrm{ml}$ at baseline to $0.26 \mathrm{ng} / \mathrm{ml}$ after legislation - a 39\% adjusted reduction in mean cotinine after implementation of the legislation $(\mathrm{P}<0.001$; table). The interaction between implementation of legislation and household smoking status was highly significant. The geometric mean for non-smokers living in non-smoking households fell from $0.35 \mathrm{ng} / \mathrm{ml}$ to $0.18 \mathrm{ng} / \mathrm{ml}$, representing a $49 \%$ reduction in mean cotinine in this group $(\mathrm{P}<0.001$; table). For non-smokers living in smoking households the fall did not reach statistical significance. 


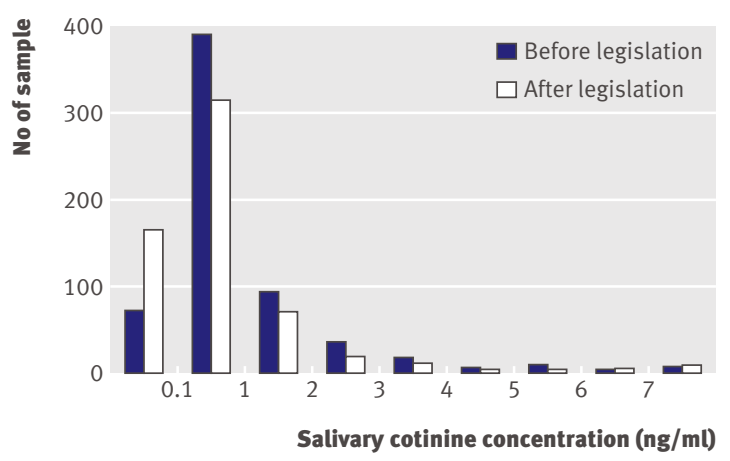

Cotinine concentrations in non-smokers before and after smoke-free legislation in Scotland

Before the legislation, non-smokers living in smoking households had levels of exposure to secondhand smoke on average 2.6 times higher than those of nonsmokers living in non-smoking households. After the legislation, levels of exposure to secondhand smoke in non-smokers living in smoking households were on average 4.5 times higher.

Reported exposure to secondhand smoke in public and private

The proportion of respondents reporting exposure to secondhand smoke fell for all locations after the legislation, but after sex, years in education, and deprivation category of residence were controlled for, reported exposure to secondhand smoke was significantly reduced only in enclosed public places covered by the legislation: in pubs (odds ratio $0.03(95 \%$ confidence interval 0.02 to $0.05 ; \mathrm{P}<0.001)$; at work $(0.32$ (0.23 to 0.45$) ; \mathrm{P}<0.001)$; on public transport $(0.29$ (0.15 to 0.57$) ; \mathrm{P}<0.001)$, and in other enclosed public places (0.25 (0.17 to 0.38); $\mathrm{P}<0.001)$. The likelihood of exposure in private enclosed places-own home, others' homes or car-did not change significantly (see table 3 on bmj.com).

\section{Reported smoking restriction in private enclosed places}

Respondents were asked about smoking restrictions in their homes and cars. After sex, years in education, and deprivation category of residence were controlled for, after the legislation, all non-smokers (irrespective of household smoking status) were more likely to report having either a complete smoking ban or a partial ban (1.49 (1.26 to 1.76$) ; \mathrm{P}<0.001)$.
Complete smoking bans in cars were more common than in homes (see table 4 on bmj.com), but after sex, deprivation category of residence, and years of education were controlled for, no change in the pattern of reported smoking restrictions in cars was observed after implementation of the legislation either overall or within the two non-smoker subgroups.

\section{DISCUSSION}

Main findings

This study provides evidence of a large reduction in secondhand smoke exposure in non-smoking adults in Scotland after implementation of legislation banning smoking in enclosed public spaces. The geometric mean salivary cotinine concentrations in adult nonsmokers fell from $0.47 \mathrm{ng} / \mathrm{ml}$ at baseline to 0.26 $\mathrm{ng} / \mathrm{ml}$ after the legislation, representing a 39\% reduction in exposure to secondhand smoke. There was a reduction in reported exposure to secondhand smoke in public places (pubs, other workplaces, and public transport) but not in private places (homes and cars). We also found no evidence of displacement of smoking into the home after implementation of Scotland's smoke-free legislation.

\section{Strengths and weaknesses of the study}

The study recruited representative samples of the Scottish population and had response rates exceeding those of other recent UK national household surveys. Both self reported and biovalidated markers of smoking status and exposure to secondhand smoke were collected. The baseline and post-legislation data were collected in the same period of the year, exactly one year apart. Our repeat cross sectional design is less robust than a longitudinal design. The samples recruited before and after legislation showed some small socioeconomic differences but these differences were controlled for in the analyses, making systematic bias unlikely. The compliance rates for provision of saliva sample for testing for cotinine were disappointing but similar to rates achieved by other UK surveys. ${ }^{8}$ There were small socioeconomic differences between respondents who agreed and those who refused to provide saliva samples, but these were controlled for in the analyses, making systematic bias unlikely. It was not feasible to include a control group from outside Scotland.

\section{Other studies}

A survey in the United States found that between 1988 and 2000 median cotinine concentrations declined by

Mean cotinine concentrations in non-smokers before and after implementation of legislation prohibiting smoking in enclosed public places

\begin{tabular}{|c|c|c|c|c|c|c|}
\hline \multirow{2}{*}{$\begin{array}{l}\text { No of smokers in } \\
\text { household }\end{array}$} & \multicolumn{2}{|c|}{ Before legislation } & \multicolumn{2}{|c|}{ After legislation } & \multicolumn{2}{|c|}{ Adjusted reduction in mean cotinine $†$} \\
\hline & No & Mean $(95 \% \mathrm{CI})^{*}$ & No & Mean $(95 \% \mathrm{Cl})^{\star}$ & $\%(95 \% \mathrm{Cl})$ & $P$ value \\
\hline None & 504 & $0.35(0.32$ to 0.39$)$ & 449 & $0.18(0.16$ to 0.20$)$ & $49(40$ to 56$)$ & $<0.001$ \\
\hline One or more & 123 & $0.92(0.74$ to 1.13$)$ & 143 & 0.81 (0.67 to 0.99$)$ & $16(-11$ to 37$)$ & $>0.05$ \\
\hline All & 627 & $0.43(0.39$ to 0.47$)$ & 592 & $0.26(0.23$ to 0.29$)$ & 39 (29 to 47$)$ & $<0.001$ \\
\hline
\end{tabular}

*Geometric mean cotinine concentrations in $\mathrm{ng} / \mathrm{ml}$, controlling for sex, years in education, and deprivation category of residence.

†Adjusted percentage reduction in geometric mean cotinine concentrations in $\mathrm{ng} / \mathrm{ml}$, controlling for sex, years in education, and deprivation category of residence. 


\section{WHAT IS ALREADY KNOWN ON THIS TOPIC}

Exposure to secondhand smoke is associated with considerable morbidity and mortality in non-smokers

Smoking bans have been shown to be effective in reducing exposure to secondhand smoke in some locations

\section{WHAT THIS STUDY ADDS}

Legislation to prohibit smoking in public places resulted in a large reduction in adult non-smokers' exposure to secondhand smoke across a whole population

After implementation of the legislation, exposure to secondhand smoke was reduced in all public places and workplaces but not in the home or private cars

The main beneficiaries of the legislation seem to be non-smokers living in non-smoking homes

The legislation did not result in increased exposure to secondhand smoke in the homes of non-smokers who lived with other smokers

more than $70 \%$ in adult non-smokers. ${ }^{9}$ A 52\% drop in mean salivary cotinine was seen in English schoolchildren between 1988 and 2003. ${ }^{10}$ These data indicate a gradual reduction in exposure to secondhand smoke in both countries. The 39\% reduction in mean cotinine concentrations in Scottish adults in our study has occurred in only one year. Most if not all of this reduction is likely to be due to the implementation of the Scottish smoke-free legislation. This strongly suggests that the legislation has rapidly reduced secondhand smoke exposure at a population level.

Similar improvements in air quality in bars and workplaces, as well as reductions in self reported exposure to secondhand smoke in public places, have been reported from elsewhere after implementation of smoke-free legislation. ${ }^{31112}$ A four country study failed to find evidence of displacement of smoking from public places into the home and found that smokefree legislation stimulated the adoption of smoke-free homes. ${ }^{13}$

Our findings are also almost identical to those of a parallel study of secondhand smoke exposure in Scottish schoolchildren. ${ }^{14}$

\section{Implications}

The reductions in exposure to secondhand smoke of the order observed in Scotland may generate immediate health gains in the Scottish population as well as longer term reductions in morbidity and mortality related to secondhand smoke. However, to our knowledge, no data are yet available to relate a reduction of this magnitude in mean cotinine concentrations in adult non-smokers to actual improvements in health at a population level. Furthermore, our study indicates that, to date, a significant reduction in exposure to secondhand smoke occurred only in non-smokers living in non-smoking households.

The now large differential in exposure to secondhand smoke between non-smokers who live in smoking and non-smoking households underlines the importance of developing interventions designed to reduce smoking in the home and in cars.

Legislation on smoking in private homes is unlikely to be effective, acceptable, or desirable, although there may be more public acceptance of restrictions on smoking in cars, especially when children are being transported. ${ }^{15}$ More could also be done to raise awareness of the health risks to adults and children associated with exposure to secondhand smoke. In particular, the finding that non-smokers exposed to low levels of tobacco smoke (relative to exposure of active smokers) are still at heightened risk of coronary heart disease needs to be communicated clearly. ${ }^{16}$

Quitting smoking is probably the most effective way of reducing secondhand smoke exposure in the home; smoking cessation services must continue to be promoted, with clear links made to the potential improvements in the health of non-smokers.

We thank Ruth Gosling. Sally Malam, and staff at BMRB Social Research, who conducted the health education population survey and prepared the database; Sonnda Catto of NHS Health Scotland who managed the commissioning of the health education population survey; and Colin Fereyabend, Mira Doig, and staff at ABS Laboratory, who advised on and performed the cotinine assays. We also thank Patricia Akhtar and Dorothy Currie of Child and Adolescent Health Research Unit, University of Edinburgh, and Rob Elton, independent consultant, for support with the analysis and presentation of results.

Contributors: See bmj.com

Funding: NHS Health Scotland and the Scottish Executive.

Competing interests: None declared.

Provenance and peer review: Not commissioned; externally peer reviewed.

1 Smoking Health and Social Care (Scotland) Act 2005, Part 1. 2005. www.opsi.gov.uk/legislation/scotland/acts2005/20050013.htm

2 Semple S, Creely KS, Naji, A Miller BJ, Ayres JG. Second hand smoke levels in Scottish pubs: the effect of the smoke-free legislation. Tob Control 2007;16:127-32.

3 Pickett M, Schober SE, Brody DJ, Curtin LR, Giovino GA. Smoke-free laws and second hand smoke exposure in US non-smoking adults, 1999-2002. Tob Control 2006;15:302-7.

4 Mulcahy M, Byrne MA, Ruprecht A. How does the Irish smoking ban measure up? A before and after study of particle concentrations in Irish pubs. J Indoor Air 2005;15(suppl ii):86.

5 Haw S, Gruer L, Amos A, Currie C, Fischbacher C, Fong GT, et al. Legislation on smoking in enclosed public places in Scotland: how will we evaluate the impact? J Pub Health 2006;28:24-30.

6 Malam S. Health education population survey (HEPS): update from 2004 survey. 2005. www.healthscotland.com/uploads/documents/ RE045Final2004.pdf

7 Bromley C, Chaudhury M, Craig R, Deverill C, Erens B, Fuller E, et al. The Scottish health survey 2003, volume 4: technical report. 2005. www.scotland.gov.uk/Publications/2005/11/25145024/50251

8 Blake M, Devrill C, Prescott A, Primatesta P, Stamatakis E. Health survey for England 2003, volume 3: methodology and documentation. 2004. www.archive2.official-documents.co.uk/ document/deps/doh/survey03/md/md-00.htm

9 US Department of Health and Human Services. Second national report on human exposure to environmental chemicals. 2003. www. jhsph.edu/ephtcenter/Second\%20Report.pdf

10 Jarvis MJ, Goddard E, Higgins V, Feyerabend C, Bryant A, Cook DG. Children's exposure to passive smoking in England since the 1980 s: cotinine evidence from population surveys. BMJ 2000;321:343-5.

11 Heloma A, Jaakkola M. Four years follow-up of smoking exposure, attitudes and smoking behaviour following enactment of Finland's smoke-free workplace law. Addiction 2003;98;1111-7.

12 Fong GT, Hyland A, Borland R, Hammond D, Hastings G, McNeill A et al. Reduction in tobacco smoke pollution and increase in support for smoke-free public places following the implementation of smokefree workplace legislation in the republic of Ireland. Tob Control 2006;15:(suppl 3);iii51-8.

13 Borland R, Yong H-H, Cummings KM, Hyland A, Anderson S, Fong GT. Determinants and consequences of smoke-free homes: findings from the International Tobacco Control (ITC) four country survey. Tob Control 2006;15(suppl 3);iii42-50.

14 Akhtar PC, Currie DB, Currie CE, Haw SJ. Changes in child exposure to environmental tobacco smoke (CHETS) study after implementation of smoke-free legislation in Scotland: national cross sectional survey. BMJ 2007;335:545-9. doi: 10.1136/bmj.39311.550197.AE.

15 Thomson G, Wilson W, Howden-Chapman P. Attitudes to, and knowledge of, second hand smoking in New Zealand homes and cars. J N Z Med Assoc 2005:118:1213.

16 Pachacek T, Babb S. How acute and reversible are the cardiovascular risks of secondhand smoke? BMJ 2004;328:980-3. 